\title{
2,2-Bis(4-Hydroxyphenyl)-1-Propanol-A Persistent Product of Bisphenol A Bio-Oxidation in Fortified Environmental Water, as Identified by HPLC/UV/ESI-MS
}

\author{
Małgorzata Drzewiecka ${ }^{1}$, Monika Beszterda ${ }^{2}$, Magdalena Frańska ${ }^{3}$ and Rafał Frański ${ }^{1, *(D)}$ \\ 1 Faculty of Chemistry Adam Mickiewicz University, Uniwersytetu Poznańskiego 8, 61-614 Poznań, Poland; \\ drzewiecka.m@onet.pl \\ 2 Department of Food Biochemistry and Analysis, Poznań University of Life Sciences, Mazowiecka 48, \\ 60-623 Poznań, Poland; monika.beszterda@gmail.com \\ 3 Institute of Chemistry and Technical Electrochemistry, Poznań University of Technology, Berdychowo 4, \\ 60-965 Poznań, Poland; magdalena.franska@put.poznan.pl \\ * Correspondence: franski@amu.edu.pl
}

check for updates

Citation: Drzewiecka, M.; Beszterda, M.; Frańska, M.; Frański, R. 2,2-Bis(4-Hydroxyphenyl)-1-

Propanol-A Persistent Product of Bisphenol A Bio-Oxidation in Fortified Environmental Water, as Identified by HPLC/UV/ESI-MS. Toxics 2021, 9, 49. https://doi.org/ $10.3390 /$ toxics 9030049

Academic Editor: James Longstaffe

Received: 4 February 2021

Accepted: 1 March 2021

Published: 5 March 2021

Publisher's Note: MDPI stays neutral with regard to jurisdictional claims in published maps and institutional affiliations.

Copyright: (c) 2021 by the authors. Licensee MDPI, Basel, Switzerland. This article is an open access article distributed under the terms and conditions of the Creative Commons Attribution (CC BY) license (https:// creativecommons.org/licenses/by/ $4.0 /)$.

\begin{abstract}
Biodegradation of bisphenol A in the environmental waters (lake, river, and sea) has been studied on the base of fortification of the samples taken and the biodegradation products have been analyzed using HPLC/UV/ESI-MS. Analysis of the characteristic fragmentation patterns of $[\mathrm{M}-\mathrm{H}]^{-}$ions permitted unambiguous identification of the biodegradation products as 2,2-bis(4hydroxyphenyl)-1-propanol or as $p$-hydroxyacetophenone, depending on the type of surface water source. The formation of 2,2-bis(4-hydroxyphenyl)-1-propanol was much more common than that of $p$-hydroxyacetophenone. Moreover, 2,2-Bis(4-hydroxyphenyl)-1-propanol has not been further biodegraded, in contrast to the $p$-hydroxyacetophenone, which was further mineralized. It has been proved, for the first time, that 2,2-bis(4-hydroxyphenyl)-1-propanol can be regarded as persistent product of bisphenol A biodegradation in the fortified environmental waters.
\end{abstract}

Keywords: bisphenol A; bio-oxidation; 2,2-bis(4-hydroxyphenyl)-1-propanol; environmental water; mass spectrometry

\section{Introduction}

Bisphenol A (BPA, 2,2-bis(4-hydroxyphenyl)propane) is a well-known precursor of plastics, mainly epoxy resins and polycarbonates, and it is one of the endocrine-disrupting chemicals produced in large volumes worldwide. The wide use of the products based on BPA implies a high possibility of environmental contamination by BPA, mainly of lakes and rivers [1]. It has prompted a vast number of studies devoted to the biodegradation of bisphenol A as recently discussed in detail in review papers [2-5].

The biodegradation processes observed in laboratory conditions reflects the processes occurring in the natural environment. However, it is well known that even a small change in the conditions can substantially affect biological processes. Therefore, it should be ascertained if the processes observed in the laboratory are really the same as those occurring in the environment. In this study, we decided to evaluate the biodegradation of BPA in the environmental waters (lake, river, and sea) by fortification with BPA in water-in laboratory conditions. To the best of our knowledge, such simple (or even trivial) experiment has not previously been performed.

In many studies, the proposed first step of BPA biodegradation pathway is BPA oxidation (bio-oxidation) and formation of two isomers shown in Scheme 1, namely, 2,2bis(4-hydroxyphenyl)-1-propanol and/or 1,2-bis(4-hydroxyphenyl)-2-propanol (further referred to as Product 1 and Product 2, respectively, Scheme 1) [6-14]. 


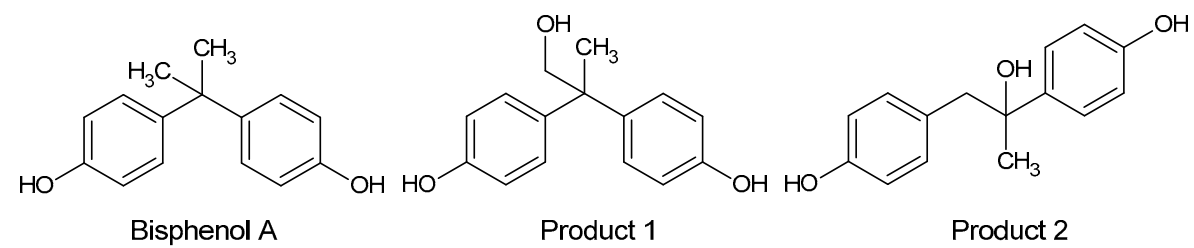

Scheme 1. Structures of bisphenol A and two biodegradation products.

This report provides the evidence, obtained by HPLC/UV /ESI-MS, for formation of 2,2-bis(4-hydroxyphenyl)-1-propanol (Product 1) as a persistent product of BPA biodegradation in the environmental waters. The second BPA biodegradation product, although, less common, was para-hydroxyacetophenone ( $p$-HAP, Scheme 2 ), which immediately underwent mineralization (decomposition to the inorganic compounds, mainly $\mathrm{CO}_{2}$ and $\mathrm{H}_{2} \mathrm{O}$ ).<smiles>CC(=O)c1ccc(O)cc1</smiles>

Scheme 2. Structure of para-hydroxyacetophenone.

From the point of view of the chemistry of the biodegradation process, the structures of biodegradation products are the most important. It is obvious that the room conditions are different from the environmental ones and may be regarded only as an approximation of the latter. On the other hand, it is likely that the biodegradation of BPA in the environment occurs in a similar way, since in our experiments, we did not change the composition of environmental water.

\section{Materials and Methods}

Bisphenol A ( $\geq 99 \%$ ) and $p$-HAP (99\%) standards were obtained from Sigma-Aldrich (Poznań, Poland) and were used without purification. The water samples used for the tests were taken in Poland from the Warta River (the main river in the region; sampling in Poznań), from the Baltic Sea (the nearest sea; sampling in Rewal), and from 10 lakes in the middle of the Wielkopolska region (Supplementary Figure S1): The water samples were collected in spring and summer, respectively. About $5 \mathrm{~L}$ of each water was collected by grab sampling into glass bottles at the depth of about $1 \mathrm{~m}$ by a sampler, leaving adequate head space for aeration and kept at a temperature of $+4{ }^{\circ} \mathrm{C}$ for no longer than $72 \mathrm{~h}$ before the biodegradation test. The $\mathrm{pH}$ of all water samples was around $\mathrm{pH}$ 7. The selected data obtained for Niepruszewo Lake, Lusowo Lake, and the Warta River are shown as representative examples.

The degradation tests were performed in $200 \mathrm{~mL}$ bottles filled with environmental water samples to which $2 \mathrm{mg}$ of BPA ( $10 \mathrm{mg} / \mathrm{L})$ were added. Similar concentrations were used by other authors for biodegradation test performance. The bottles were kept at room temperature $\left(20-25^{\circ} \mathrm{C}\right)$, opened, and exposed to the day sunlight. Every fifth day, $1 \mathrm{~mL}$ was collected from each bottle and $0.5 \mathrm{~mL}$ of methanol was added to it, and the mixtures were placed in the fridge, to cease the biodegradation process. The samples were collected over 3 months and then subjected to HPLC/UV/ESI-MS analysis.

The HPLC/UV /ESI-MS analyses were made on a Waters model 2690 HPLC pump (Milford, MA, USA), Waters 996 Photodiode Array Detector and Waters/Micromass ZQ2000 mass spectrometer (single quadrupole type instrument equipped with electrospray ion source, Z-spray, Manchester, UK). The HPLC/UV and HPLC/MS are the two most commonly used methods used for analysis of bisphenol A and its metabolites [15-18]. The software used was MassLynx V3.5 (Manchester, UK). Using an autosampler, the sample solutions were injected onto the XTerra ${ }^{\circledR} \mathrm{RP} 18$ column $(5 \mu \mathrm{m}, 150 \mathrm{~mm} \times 3 \mathrm{~mm}$ i.d.; Waters, Warsaw, Poland). The injection volume was $10 \mu \mathrm{L}$. The solutions were analyzed using 
linear gradient of $\mathrm{CH}_{3} \mathrm{CN}-\mathrm{H}_{2} \mathrm{O}$ with a flow rate of $0.4 \mathrm{~mL} / \mathrm{min}$. Two gradients were used, namely, acidified and non-acidified. We found that acidified gradient was better for UVVIS detection and non-acidified was better for MS detection (MS detection was performed in negative ion mode). The acidified gradient started from $0 \% \mathrm{CH}_{3} \mathrm{CN}-95 \% \mathrm{H}_{2} \mathrm{O}$ with $5 \%$ of a $10 \%$ solution of formic acid in water, reaching $95 \% \mathrm{CH}_{3} \mathrm{CN}$ after $30 \mathrm{~min}$, and the latter concentration was kept for $10 \mathrm{~min}$. The non-acidified gradient started from $5 \% \mathrm{CH}_{3} \mathrm{CN}-$ $95 \% \mathrm{H}_{2} \mathrm{O}$, reaching $95 \% \mathrm{CH}_{3} \mathrm{CN}$ after $30 \mathrm{~min}$, and the latter concentration was kept for 10 min. Thus, the full time of HPLC/ESI-MS analysis was $40 \mathrm{~min}$, however, for the sake of clarity, the chromatograms are shown for a smaller time range. As expected, HPLC/UV yielded better linearity (signal intensities vs. compound concentration, Supplementary Figure S2), whereas HPLC/ESI-MS allowed identification of biodegradation products.

The UV-VIS spectra were recorded in the range of 210-600 nm. The BPA and its degradation products were monitored by absorbance at $280 \mathrm{~nm}[6,7,19-24]$. For each sample, the analyses were performed three times and the calculated relative standard deviations for the peak areas obtained upon HPLC/UV analysis did not exceed 5\%.

The ESI mass spectra were recorded in the $m / z$ range of 70-1000, in negative ion mode. The electrospray source potentials were: capillary $3 \mathrm{kV}$, lens $0.5 \mathrm{kV}$, extractor $4 \mathrm{~V}$, and cone voltage 30-80 V. It is known that cone voltage has the greatest impact on the mass spectra recorded. Increase in this parameter leads to the so-called "in-source" fragmentation/dissociation but a too low cone voltage may cause a decrease in sensitivity. The source temperature was $120^{\circ} \mathrm{C}$, and the desolvation temperature was $300^{\circ} \mathrm{C}$. Nitrogen was used as the nebulizing and desolvation gas at the flow rates of 100 and $300 \mathrm{~L} / \mathrm{h}$, respectively.

To corroborate the structures and fragmentation patterns of Product 1, we collected the eluate containing this compound (in the proper range of retention time) and then the eluate was directly infused into the Q-TOF mass spectrometer (coupling off-line of HPLC to ESI-MS/MS), as described in the Supplementary Material.

\section{Results and Discussion}

At first, it has to be checked if we really deal with a biodegradation process, and not with simple BPA oxidation by air. Therefore, BPA has been also added to pure water (the tap water used was purified/deionized using demineralizer). It has to be stressed that in pure water, even after 3 months, the BPA concentration was not lowered (Supplementary Figure S3). When BPA was added to the environmental water from a lake or river, after several days, its concentration started to decrease. When BPA was added to the sea water, its concentration was only slightly decreased after several dozen days, no biodegradation products were detected (Supplementary Figure S4).

Figure 1 shows exemplary UV chromatograms. When BPA was stored in samples of environmental water, its concentration decrease was accompanied by an increase in the concentration the compounds characterized with a retention time of $12.6 \mathrm{~min}$ (Figure 1), for most of the fortified environmental water samples.

Exemplary breakdown plots of chromatographic peak areas (chromatograms obtained at $280 \mathrm{~nm}$ ) against days of biodegradation test are presented in Figure 2. The peak areas expressed in arbitrary units were converted into percentages (the largest peak is assumed as $100 \%)$. 


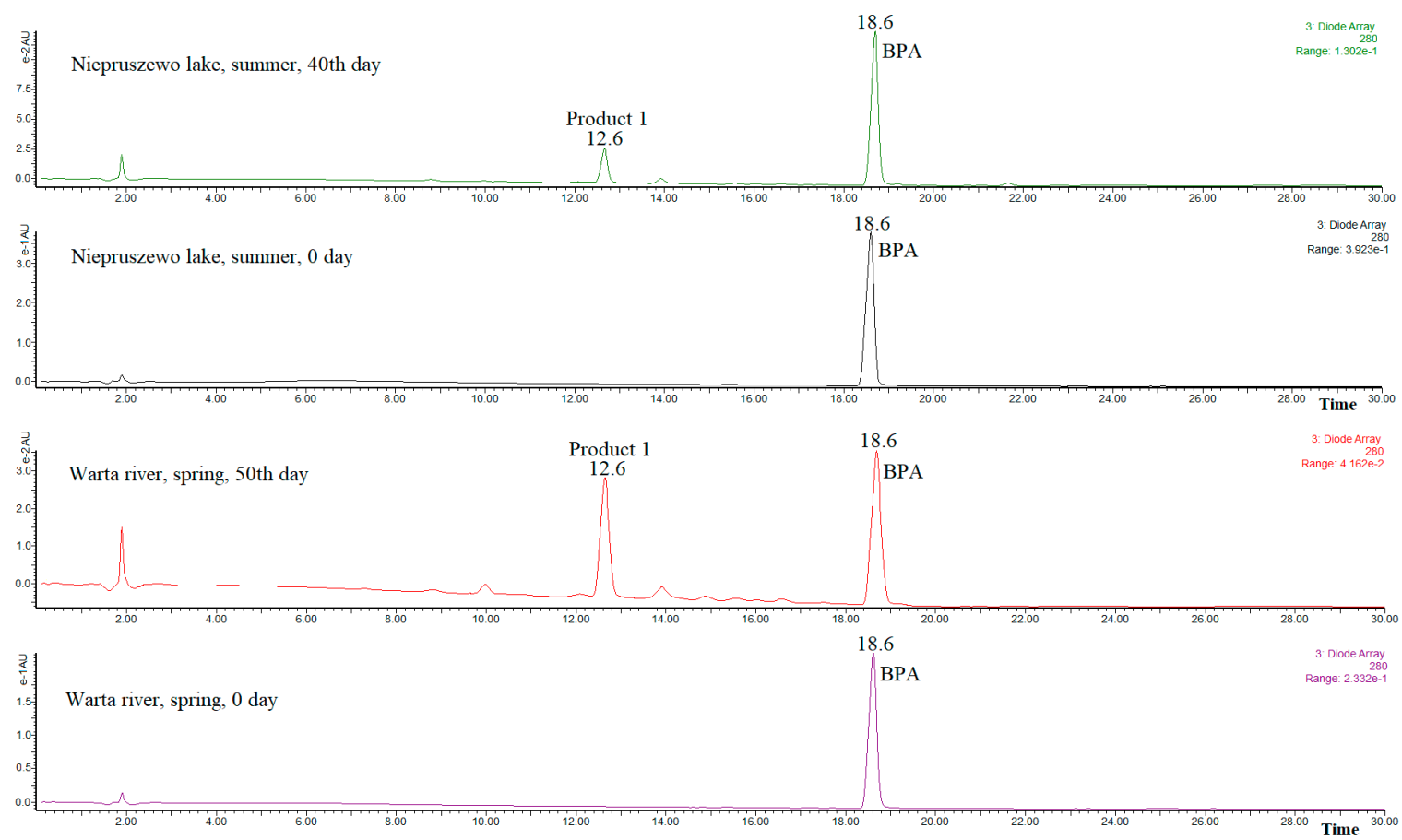

Figure 1. Exemplary UV chromatograms obtained at $280 \mathrm{~nm}$ (acidified gradient).
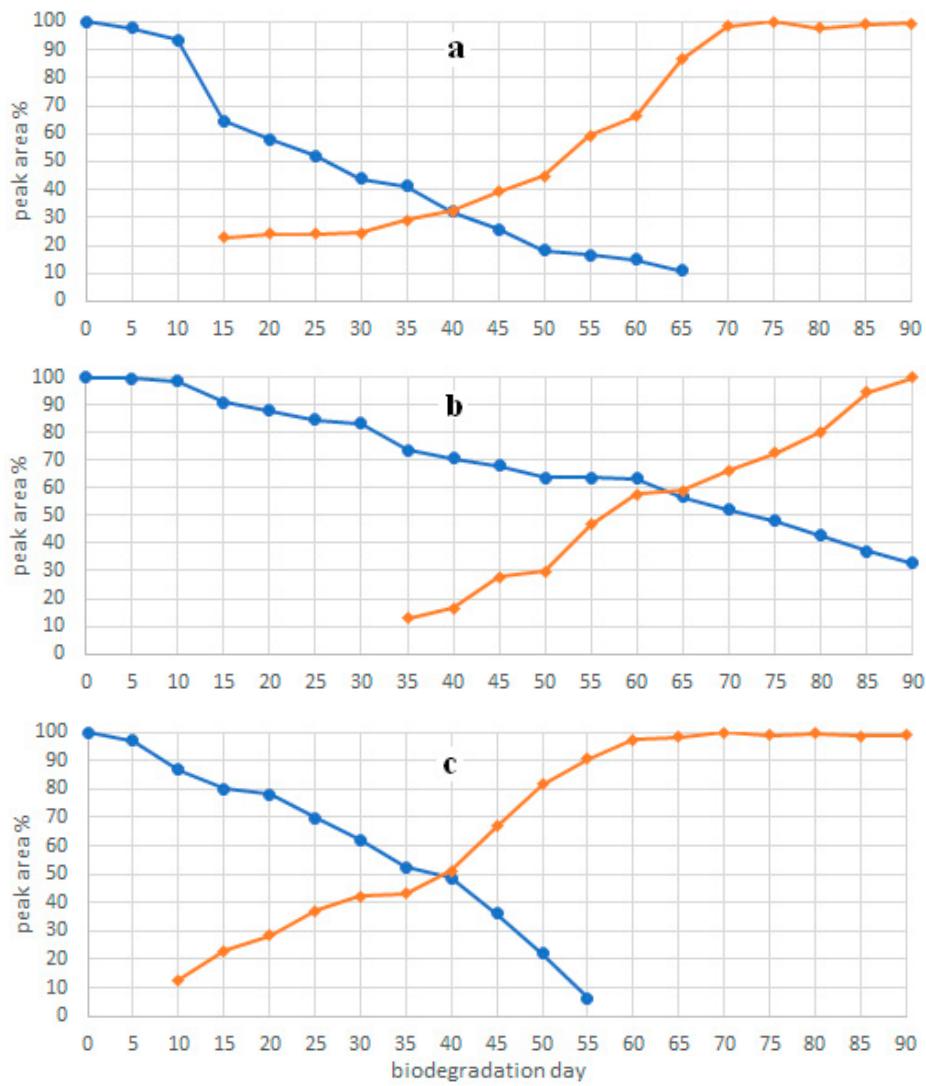

Figure 2. Exemplary breakdown plots of chromatographic peak areas (UV chromatogram at $280 \mathrm{~nm}$ ) against days of biodegradation test bisphenol A (BPA) (BPA was added to water samples at $10 \mathrm{mg} / \mathrm{L}$ on day $0, \because$ BPA, $\rightarrow$ Product 1 ): (a) Niepruszewo lake, summer; (b) Niepruszewo lake, spring; and (c) Warta river, spring. 
As clearly seen from Figure 2, the rate of BPA biodegradation strongly depends on the source of environmental water taken for the test. However, in each test, the biodegradation product characterized with a retention time of $12.6 \mathrm{~min}$ was not further degraded.

HPLC/ESI-MS analyses have indicated that molecular mass of the biodegradation product at the retention time of $12.6 \mathrm{~min}$ is 244 (ion [M-H] $]^{-}$at $\mathrm{m} / \mathrm{z} 243$ ). In order to unambiguously determine the structure of the biodegradation product, we performed the HPLC/UV/ESI-MS analysis using non-acidified gradient, since it allowed obtaining much higher signals to noise ratio of ions $[\mathrm{M}-\mathrm{H}]^{-}$and product ions. Figure 3 shows the exemplary chromatograms obtained using non-acidified gradient.

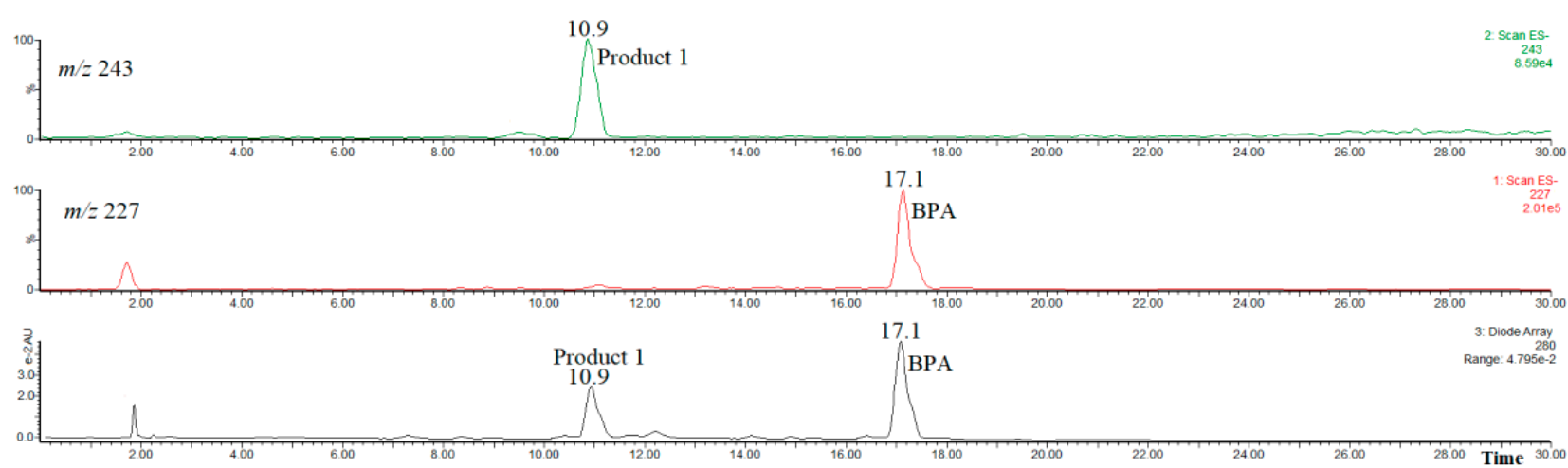

Figure 3. Exemplary HPLC/UV chromatograms obtained at $280 \mathrm{~nm}$ and single ion chromatograms of ions at $m / z 227$ and $243\left([\mathrm{M}-\mathrm{H}]^{-}\right.$of BPA and Product 1, respectively) obtained using non-acidified gradient (Niepruszewo lake, summer, 45 th day).

The HPLC/ESI-MS analysis performed using high cone voltage allowed obtaining a fragmentation pathway and, as a consequence, allowed determination of the structure of Product 1. Namely, at a high cone voltage, the abundant fragment ion at $m / z 211$ was formed as shown in Figure 4 and in the Supplementary Material (Supplementary Figure S5).

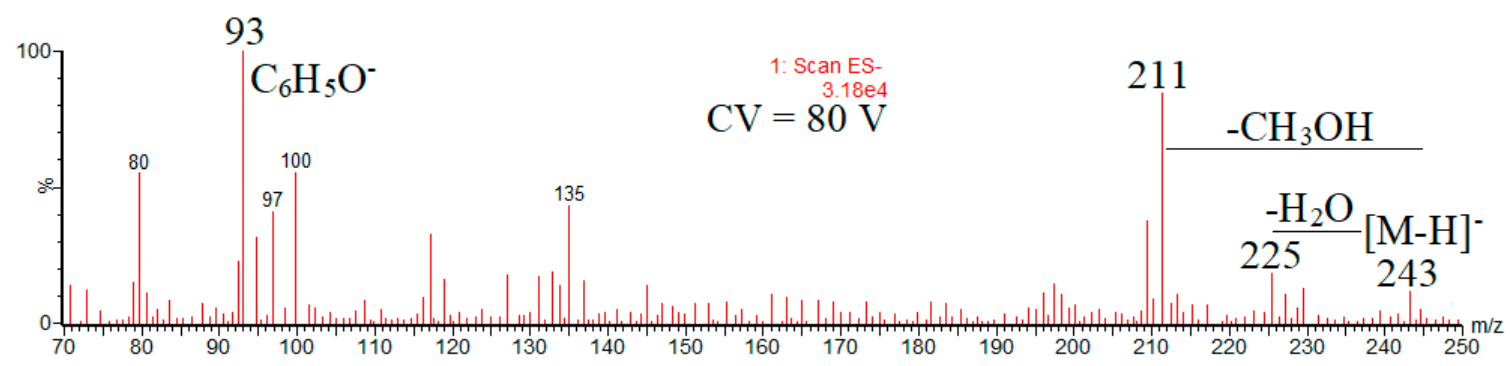

Figure 4. Electrospray ionization mass spectrum of Product 1 obtained at high cone voltage (we have checked if the fragment ions have identical retention time as $[\mathrm{M}-\mathrm{H}]^{-}$, otherwise we deal with background ions).

The product ion at $m / z 211$ was formed by the loss of methanol from $[\mathrm{M}-\mathrm{H}]^{-}$ion, and formation of this fragment ion cannot be expected for Product 2 (Scheme 1). In view of the above, the fragment ion at $m / z 211$ can be treated as a diagnostic ion proving that we deal with Product 1 . The product ion spectra (collision-induced dissociationMS/MS) obtained using a Q-TOF mass spectrometer confirmed the fragmentation pattern of Product 1 (Supplementary Figure S6). On the other hand, our results are different from those described by Sasaki et al. who have observed identical fragmentation patterns for Product 1 and 2, regardless of minor differences in relative ion abundances [10].

Theoretically, it is possible that we deal with bio-oxidation in aromatic ring and formation of 2-(4-hydroxyphenyl)-2-(3', $4^{\prime}$-dihydroxyphenyl)propane, however, the frag- 
mentation pattern of this compound is substantially different than that observed in our work $[22,25,26]$.

BPA is estrogenic and antiandrogenic compound, whereas 2,2-bis(4-hydroxy-phenyl)1-propanol is weekly estrogenic, non-antiandrogenic, and less toxic than parent compound in in vitro and in vivo reporter assays [27]. As indicated by Suzuki et al. 2,2-bis(4hydroxyphenyl)-1-propanol and 2-(4-hydroxyphenyl)-2-( $3^{\prime}, 4^{\prime}$-dihydroxyphenyl) propane displaced the $17 \beta$-estradiol bound to the ERa (estrogen receptor $\alpha$ ) in a competitive manner, however, the competitive potency of these compounds was 50 times less than that of diethylstilbesterol [11]. Moreover, in human cultured MCF-7 breast cancer cells, 2,2-bis(4hydroxyphenyl)-1-propanol did not cause proliferation. Therefore, bio-oxidation of BPA into 2,2-bis(4-hydroxyphenyl)-1-propanol seems to be justified.

Only for two of the biodegradation tests, a biodegradation pathway different than that described above has been observed. Namely, the biodegradation product characterized by a retention time of 10.3 min was observed as shown in Figure 5.

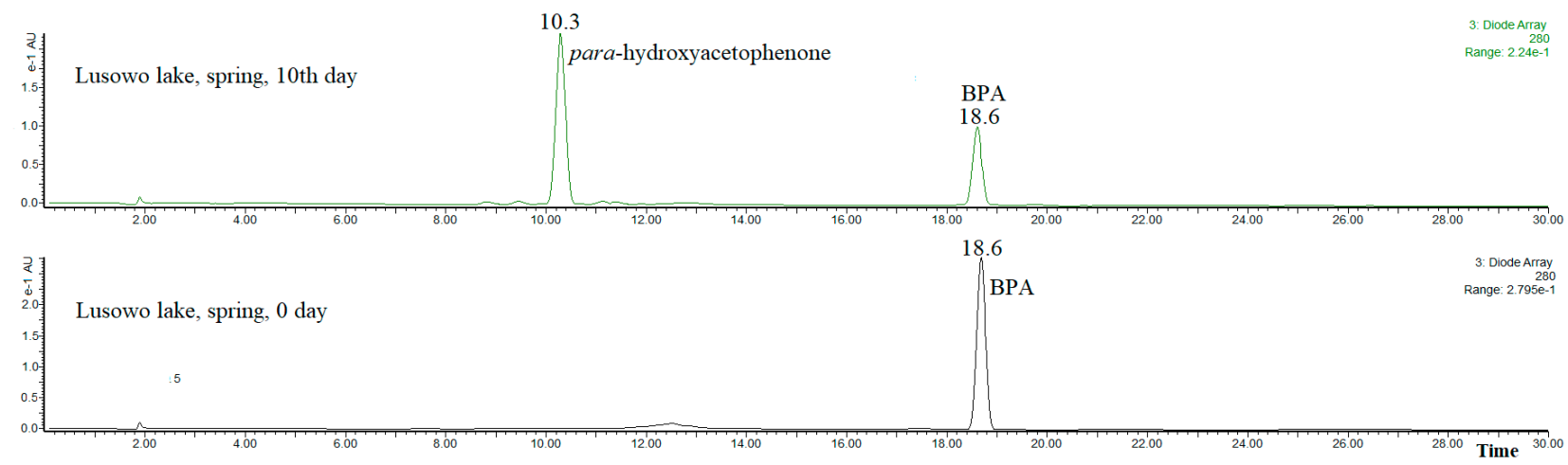

Figure 5. Exemplary UV chromatograms obtained at $280 \mathrm{~nm}$ (non-acidified gradient).

The $m / z 135$ of $[\mathrm{M}-\mathrm{H}]^{-}$ion and fragment ions at $m / z$ 120, 93, 92 (Supplementary Figures S7 and S8) indicate that it is para-hydroxyacetophenone ( $p$-HAP, piceol) [28,29]. The HPLC/UV/ESI-MS analysis of $p$-HAP standard fully confirmed the structure of the biodegradation product characterized by the retention time $10.3 \mathrm{~min}$. Figure 6 shows the breakdown plots of chromatographic peak areas against days of biodegradation test, for the test in which $p$-HAP was formed.

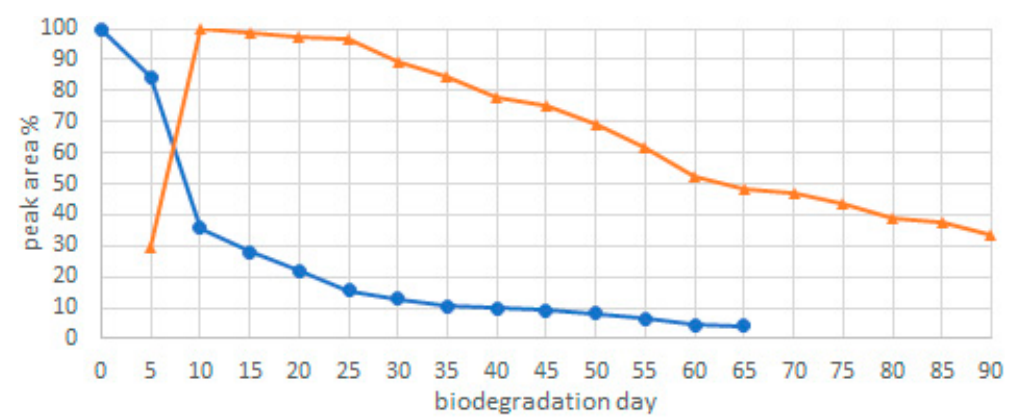

Figure 6. The breakdown plot of chromatographic peak areas (UV chromatogram at $280 \mathrm{~nm}$ ) against days of biodegradation test obtained for Lusowo lake, spring ( $\bullet \mathrm{BPA},-p$-HAP).

In contrast to Product 1, $p$-HAP is not a persistent biodegradation product, since it is also biodegraded, as shown in Figure 6. After the initial concentration increase, its concentration decrease was observed, however, its further metabolites were not detected.

It has to be stressed that $p$-HAP can be formed from 1,2-bis(4-hydroxyphenyl)-2-propanol (Product 2, Scheme 1) as suggested in a number of papers [4,5,7-9,11-14,21,30-32]. Therefore, bio-oxidation of BPA into Product 2 in the environmental water is possible, however, Product 2 is immediately converted into $p$-HAP (most probably through 4,4'-dihydroxy- 
$\alpha$-methylstilbene). Furthermore, it has been also suggested that the produced $p$-HAP is further mineralized $[4,7,9,11,14,30,32]$, it can explain why further metabolites of $p$-HAP have not been detected.

As indicated by Ike et al. (2002), the acute toxicity and estrogenicity of BPA can be considerably eliminated by aerobic biodegradation [33]. Among above products $p$-HAP shows much lower toxicity than BPA, lack of mutagenic activity, however, might have a weak estrogenicity understood as dose-dependent increase in $\beta$-galactosidase activity [34].

\section{Conclusions}

It has been proved that under the conditions used, two BPA biodegradation pathways in the environmental waters are possible. The first, most common, is the BPA bio-oxidation and leads to the formation of 2,2-bis(4-hydroxyphenyl)-1-propanol, which is not further biodegraded, thus 2,2-bis(4-hydroxyphenyl)-1-propanol can be regarded as a persistent BPA metabolite. The second, less common, pathway is the formation of $p$-HAP, which is further mineralized. Of course, as the target is to maintain water purity, the second pathway seems to be more desirable. In order to explain why sometimes the BPA biodegradation comprises the formation of 2,2-bis(4-hydroxyphenyl)-1-propanol (Product 1, Scheme 1) and sometimes the formation of $p$-HAP, detailed biological studies should be performed.

Supplementary Materials: The following are available online at https:/ / www.mdpi.com/2305-630 4/9/3/49/s1, Figure S1: Approximate water sampling sites from Baltic Sea, Warta River and local lakes. Figure S2: Linearity obtained during HPLC/UV and HPLC/MS analysis of bisphenol A (BPA) solutions (peak area is in the arbitrary units). Figure S3: Exemplary UV chromatograms obtained at $280 \mathrm{~nm}$ (acidified gradient) for BPA stored at sea pure water; the biodegradation process has not been observed. Figure S4: Exemplary UV chromatograms obtained at $280 \mathrm{~nm}$ (acidified gradient) for BPA stored at sea water; very slow biodegradation process has been observed. Figure S5: Electrospray ionization mass spectra of Product 1 obtained at different cone voltages (CV); we have checked if the fragment ions have identical retention time as $[\mathrm{M}-\mathrm{H}]^{-}$, otherwise we deal with background ions. Figure S6: Product ion spectra of [M-H] ${ }^{-}$ion of 2,2-bis(4-hydroxyphenyl)-1-propanol. Figure S7: Exemplary HPLC/UV chromatograms obtained at $280 \mathrm{~nm}$ and single ion chromatograms of ions at $\mathrm{m} / \mathrm{z} 227$ and 135 ([M-H] ${ }^{-}$of BPA and para-hydroxyacetophenone ( $p$-HAP), respectively) obtained using non-acidified gradient. Figure S8: Exemplary ESI mass spectra of $p$-HAP.

Author Contributions: Conceptualization: M.B. and R.F.; methodology: M.B. and M.F.; formal analysis and investigation: M.D. and R.F.; writing—original draft preparation: M.B., M.F., M.D., and R.F.; writing—review and editing: R.F.; funding acquisition: M.B., M.F. and R.F. All authors have read and agreed to the published version of the manuscript.

Funding: This work was supported by the Ministry of Science and Higher Education, Poland.

Institutional Review Board Statement: Not applicable.

Informed Consent Statement: Not applicable.

Conflicts of Interest: The authors declare no conflict of interest.

\section{References}

1. Liu, J.; Zhang, L.; Lu, G.; Jiang, R.; Yan, Z.; Li, Y. Occurrence, toxicity and ecological risk of Bisphenol A analogues in aquatic environment-A review. Ecotoxicol. Environ. Saf. 2021, 208, 111481. [CrossRef]

2. Im, J.; Löffler, F.E. Fate of bisphenol A in terrestrial and aquatic environments. Environ. Sci. Technol. 2016, 50, 8403-8416. [CrossRef]

3. Kang, J.-H.; Katayama, Y.; Kondo, F. Biodegradation or metabolism of bisphenol A: From microorganisms to mammals. Toxicology 2006, 217, 81-90. [CrossRef]

4. Noszczyńska, M.; Piotrowska-Seget, Z. Bisphenols: Application, occurrence, safety, and biodegradation mediated by bacterial communities in wastewater treatment plants and rivers. Chemosphere 2018, 201, 214-223. [CrossRef] [PubMed]

5. Sánchez, C. Microbial capability for the degradation of chemical additives present in petroleum-based plastic products: A review on current status and perspectives. J. Hazard. Mater. 2021, 402, 123534.

6. $\quad$ Peng, Y.-H.; Chen, Y.-J.; Chang, Y.-J.; Shih, Y. Biodegradation of bisphenol A with diverse microorganisms from river sediment. J. Hazard. Mater. 2015, 286, 285-290. [CrossRef] 
7. Ike, M.; Jin, C.S.; Fujita, M. Biodegradation of bisphenol A in the aquatic environment. Water Sci. Technol. 2000, 42, 31-38. [CrossRef]

8. Wang, W.; Yu, H.; Qin, H.; Longa, Y.; Ye, J.; Qu, Y. Bisphenol A degradation pathway and associated metabolic networks in Escherichia coli harboring the gene encoding CYP450. J. Hazard. Mater. 2020, 88, 121737. [CrossRef]

9. Eltoukhy, A.; Jia, Y.; Nahurira, R.; Abo-Kadoum, M.A.; Khokhar, I.; Wang, J.; Yan, Y. Biodegradation of endocrine disruptor Bisphenol A by Pseudomonas putida strain YC-AE1 isolated from polluted soil, Guangdong, China. BMC Microbiol. 2020, $20,11$. [CrossRef]

10. Sasaki, M.; Akahira, A.; Oshiman, K.; Tsuchido, T.; Matsumura, Y. Purification of cytochrome P450 and ferredoxin, involved in bisphenol A degradation, from Sphingomonas sp. Strain AO1. Appl. Environ. Microbiol. 2005, 71, 8024-8030. [CrossRef] [PubMed]

11. Suzuki, T.; Nakagawa, Y.; Kano, I.; Yaguchi, K.; Yasuda, K. Environmental fate of Bisphenol A and its biological metabolites in river water and their xeno-estrogenic activity. Environ. Sci. Technol. 2004, 38, 2389-2396. [CrossRef] [PubMed]

12. Das, R.; Liang, Z.; Li, G.; Mai, B.; An, T. Genome sequence of a spore-laccase forming, BPA-degrading Bacillus sp. GZB isolated from an electronic-waste recycling site reveals insights into BPA degradation pathways. Arch. Microbiol. 2019, 201, 623-638. [CrossRef]

13. Eio, E.J.; Kawai, M.; Tsuchiya, K.; Yamamoto, S.; Toda, T. Biodegradation of bisphenol A by bacterial consortia. Int. Biodeterior. Biodegrad. 2014, 96, 166-173. [CrossRef]

14. Spivack, J.; Leib, T.K.; Lobos, J.H. Novel pathway for bacterial metabolism of Bisphenol A. Rearrangements and stilbene cleavage in Bisphenol A metabolism. J. Biol. Chem. 1994, 269, 7323-7329. [CrossRef]

15. Salgueiro-González, N.; Castiglioni, S.; Zuccato, E.; Turnes-Carou, I.; López-Mahía, P.; Muniategui-Lorenzo, S. Recent advances in analytical methods for the determination of 4-alkylphenols and bisphenol A in solid environmental matrices: A critical review. Anal. Chim. Acta 2018, 1024, 39-51. [CrossRef]

16. Salgueiro-González, N.; Muniategui-Lorenzo, S.; López-Mahía, P.; Prada-Rodríguez, D. Trends in analytical methodologies for the determination of alkylphenols and bisphenol A in water samples. Anal. Chim. Acta 2017, 962, 1-14. [CrossRef]

17. Sun, F.; Kang, L.; Xiang, X.; Li, H.; Luo, X.; Luo, R.; Lu, C.; Peng, X. Recent advances and progress in the detection of bisphenol A. Anal. Bioanal. Chem. 2016, 408, 6913-6927. [CrossRef] [PubMed]

18. Cao, X.-L. A review recent development on analytical methods for determination of bisphenol a in food and biological samples. J. Liq. Chromatogr. Relat. Technol. 2012, 35, 2795-2829. [CrossRef]

19. Danzl, E.; Sei, K.; Soda, S.; Ike, M.; Fujita, M. Biodegradation of Bisphenol A, Bisphenol F and Bisphenol S in seawater. Int. J. Environ. Res. Public Health 2009, 6, 1472-1484. [CrossRef] [PubMed]

20. Louati, I.; Dammak, M.; Nasri, R.; Belbahri, L.; Nasri, M.; Abdelkafi, S.; Mechichi, T. Biodegradation and detoxification of bisphenol A by bacteria isolated from desert soils. 3 Biotech 2019, 9, 228. [CrossRef] [PubMed]

21. Babatabar, S.; Zamir, S.M.; Shojaosadati, S.A.; Yakhchali, B.; Zarch, A.B. Cometabolic degradation of bisphenol A by pure culture of Ralstonia eutropha and metabolic pathway analysis. J. Biosci. Bioeng. 2019, 127, 732-737. [CrossRef] [PubMed]

22. Deborde, M.; Rabouan, S.; Mazellier, P.; Duguet, J.P.; Legube, B. Oxidation of bisphenol A by ozone in aqueous solution. Water Res. 2008, 42, 4299-4308. [CrossRef] [PubMed]

23. Yoon, Y.; Westerhoff, P.; Snyder, S.A.; Esparz, M. HPLC-fluorescence detection and adsorption of bisphenol A, 17 $\beta$-estradiol, and $17 \alpha$-ethynyl estradiol on powdered activated carbon. Water Res. 2003, 37, 3530-3537. [CrossRef]

24. Putman, L.; Nyland, C.; Parson, K. Green disposal of waste bisphenol A. Phys. Sci. Rev. 2016, 1, 20160075. [CrossRef]

25. Xu, J.; Zhao, C.; Wang, T.; Yang, S.; Liu, Z. Photo-oxidation of Bisphenol A in aqueous solutions at near neutral pH by a Fe(III)-carboxylate complex with oxalacetic acid as a benign molecule. Molecules 2018, 23, 1319. [CrossRef]

26. Qiu, Y.; Wang, L.; Leung, C.; Liu, G.; Yang, S.; Lau, T.C. Preparation of nitrogen doped $\mathrm{K}_{2} \mathrm{Nb}_{4} \mathrm{O}_{11}$ with high photocatalytic activity for degradation of organic pollutants. Appl. Catal. A Gen. 2011, 402, 23-30. [CrossRef]

27. Kitamura, S.; Suzuki, T.; Sanoh, S.; Kohta, R.; Jinno, N.; Sugihara, K.; Yoshihara, S.; Fujimoto, N.; Watanabe, H.; Ohta, S. Comparative study of the endocrine-disrupting activity of Bisphenol A and 19 related compounds. Toxicol. Sci. 2005, 84, 249-259. [CrossRef]

28. Liu, H.; Chen, M.; Yin, H.; Hu, P.; Wang, Y.; Liu, F.; Tian, X.; Huang, C. Exploration of the hepatoprotective chemical base of an orally administered herbal formulation (YCHT) in normal and CCl4-intoxicated liver injury rats. Part 1: Metabolic profiles from the liver-centric perspective. J. Ethnopharmacol. 2019, 237, 81-91. [CrossRef]

29. Attygalle, A.B.; Ruzicka, J.; Varughese, D.; Bialecki, J.B.; Jafri, S. Low-energy collision-induced fragmentation of negative ions derived from ortho-, meta-, and para-hydroxyphenyl carbaldehydes, ketones, and related compounds. J. Mass Spectrom. 2007, 42, 1207-1217. [CrossRef]

30. Horikoshi, S.; Tokunaga, A.; Hidaka, H.; Nerpone, N. Environmental remediation by an integrated microwave/UV illumination method VII. Thermal/non-thermal effects in the microwave-assisted photocatalyzed mineralization of bisphenol-A. J. Photochem. Photobiol. A Chem. 2004, 162, 33-40. [CrossRef]

31. Vo, H.N.P.; Ngo, H.H.; Guo, W.; Nguyen, K.H.; Chang, S.W.; Nguyen, D.D.; Liu, Y.; Liu, Y.; Ding, A.; Bui, X.T. Micropollutants cometabolism of microalgae for wastewater remediation: Effect of carbon sources to cometabolism and degradation products. Water Res. 2020, 183, 115974. [CrossRef] 
32. Zhou, N.A.; Kjeldal, H.; Gough, H.L.; Nielsen, J.L. Identification of putative genes involved in Bisphenol A degradation using differential protein abundance analysis of Sphingobium sp. BiD32. Environ. Sci. Technol. 2015, 49, 12232-12241. [CrossRef] [PubMed]

33. Ike, M.; Chen, M.Y.; Jin, C.S.; Fujita, M. Acute toxicity, mutagenicity, and estrogenicity of biodegradation products of bisphenol-A. Environ. Toxicol. Int. J. 2002, 17, 457-461. [CrossRef] [PubMed]

34. Jin, L.; Dai, J.; Guo, P.; Wang, L.; Wei, Z.; Zhang, Z. Quantitative structure-toxicity relationships for benzaldehydes to Daphnia magna. Chemosphere 1998, 37, 79-85. [CrossRef] 